\title{
0 projeto experimental: Uma experiência do curso de Relações Públicas da UFG
}

\section{The Experimental Projects: Public Relations Course of Universidade Federal de Goiás}

\author{
Maria Francisca Magalhães \\ Mestre em Ciências da Comunicação pela USP e professora de Comunicação Social da UFG \\ E-mail:fnogueira@cultura.com.br \\ Luciana Ribeiro Carneiro Silva, ex-aluna e orientanda desse projeto.
}

Resumo

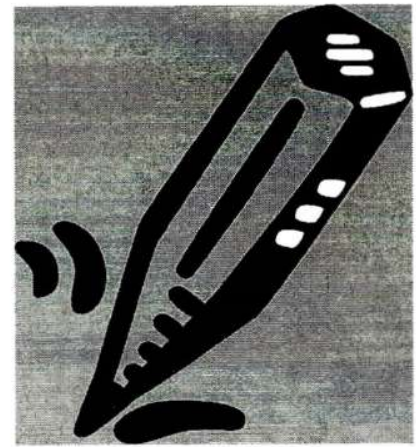

"Projeto Experimental" é uma disciplina do último ano do curso de Comunicação Social e, como tal, vem desempenhando papel importante na formação dos alunos. No ano de 2004, com o objetivo de ampliar a compreensão acerca dessa prática pedagógica, desenvolveu-se uma pesquisa com alunos e professores do último ano do curso de Relações Públicas da Faculdade de Comunicação e Biblioteconomia, da Universidade Federal de Goiás. 0 objetivo deste artigo é tão-somente abordar alguns pontos relevantes dessa pesquisa e, dessa forma, contribuir para que alunos e professores de Comunicação Social tenham uma reflexão sobre o assunto.

Palavras-chave: projetos experimentais; relações públicas; comunicação.

\section{Introdução}

Os Projetos Experimentais de Relaçōes Públicas foram adotados no Brasil como uma disciplina mais profissionalizante, no Departamento de Relaçóes Públicas da Escola de Comunicação e Artes da Universidade de São Paulo (ECA/USP), no início da década de 1970, visando aliar a prática à teoria. A partir de então, projetos experimentais (PE) têm figurado nas escolas de Comunicação Social como trabalho de final de curso, de caráter essencialmente prático, enquanto os Trabalhos de Conclusão de Curso (TCC) assumiram um caráter mais teórico ou monográfico (KUNSCH, 1987).

Ainda hoje, segundo Moura (1997), as discussōes que abordam o eterno paralelo entre teoria e prática estão presentes na maioria dos cursos de Comunicação Social. Na Universidade Federal de Goiás (UFG), esse questionamento começou a desabrochar no final dos anos 1970, quando se percebeu a necessidade de adequação da graduação ao que o mercado esperava dos profissionais de Comunicação Social. Nesse contexto, surgem os projetos experimentais, com o objetivo de melhorar o ensino oferecido aos estudantes, além de lhes proporcionar oportunidades de conhecer o mercado e interagir com ele.

O curso de Relaçōes Públicas da UFG, que foi reconhecido pelo decreto 83.336 de 16 de abril de 1979 , nesse mesmo ano introduziu o projeto experimental como disciplina. Desde então, projetos experimentais vêm desempenhando papel importante na formação dos seus alunos. Nessa disciplina, que pode ter um papel estratégico, pois oferece ao aluno a oportunidade de aliar prática e teoria, desenvolvem-se projetos para clientes reais. Freitas e França (1997) enfatizam que o projeto também colabora na divulgação e promoção do curso, além de inserir o jovem profissional no mercado de trabalho. Além disso, o Projeto Experimental também "educa" o empresariado sobre o que são as Relaçôes Públicas e para que elas servem.

Para se compreender melhor essa disciplina no curso de Relaçōes Públicas da Faculdade de Comunicação e Biblioteconomia (Facomb/UFG), desenvolveu-se, em 2004, uma pesquisa com os alunos do último ano e com os cinco professores efetivos do curso. Esse trabalho teve como objetivo analisar a 
importância dos Projetos Experimentais (PE) na formação acadêmica dos alunos de Relaçōes Públicas da UFG.

O trabalho foi desenvolvido em duas etapas: a pesquisa bibliográfica e a pesquisa de campo. A pesquisa bibliográfica possibilitou realizar uma reflexão sobre o objeto em estudo $\mathrm{e}$, nessa orientação, colaborou para a ampliação do conhecimento acerca da história dos projetos experimentais e sua evolução. A pesquisa de campo permitiu coletar dados importantes, com os projetos realizados no período de 1999 a 2003, sobre o comportamento dos alunos, a opinião dos professores orientadores, as principais dificuldades enfrentadas pelos alunos.

A pesquisa de campo valeu-se de um questionário e da formação de um grupo focal. A aplicação do questionário - método mais direto e anônimo, que possibilita revelar pontos de vista e opiniōes não conhecidos anteriormente - teve como função "quantificar" as opiniōes de alunos e professores. O grupo focal funcionou como um mediador de opiniăo mais eficaz, pois, em grupo, as opiniōes puderam ser confrontadas e debatidas. Além disso, com o grupo focal foi possível confrontar as opiniōes com o levantamento feito pelo questionário, contribuindo assim para um trabalho mais completo.

Este artigo não pretende se $\|$

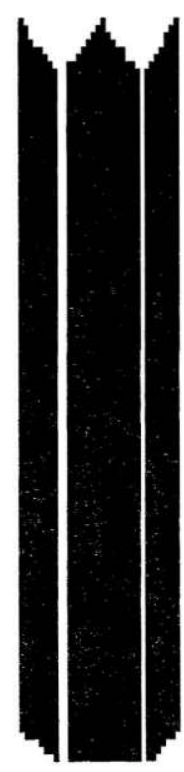
aprofundar nos resultados da pesquisa, mas apenas apresentar pontos relevantes e, dessa forma, contribuir para que alunos e professores de comunicação tenham uma reflexão acerca dessa prática pedagógica.

\section{O Projeto Experimental na UFG}

Atualmente, o curso de Relações Públicas conta com cinco professores efetivos, quatro com formaçăo em Relaçôes Públicas e um com formação em Jornalismo. Ocasionalmente, dispõe de professores substitutos. O restrito número de docentes efetivos vem acarretando problemas. Dentre eles, a sobrecarga de disciplinas para os professores e um revezamento grande de docentes durante os quatro anos letivos.
Em muitas ocasiōes, um professor ministra duas disciplinas para uma mesma turma durante todo o ano. Esse quadro provoca uma reduçáo no ânimo de alunos e professores e, conseqüentemente, enfraquece a produção do debate, diferencial do ensino acadêmico.

Para contornar o problema do número limitado de professores específicos de Relaçōes Públicas quanto à orientação dos projetos experimentais, os professores recomendam que os alunos o façam em grupo. Em sua maioria, os grupos constituem-se de quatro ou cinco componentes, número máximo permitido pelos professores. De acordo com levantamento realizado, os alunos, em sua maioria, realizam os projetos práticos em grupos de quatro componentes.

Diante da sobrecarga a que são submetidos - além das orientaçōes, há inúmeras atribuiçōes, tais como regência de sala, acompanhamento de projetos de pesquisa e extensão, participação em reuniōes e bancas de concurso etc. - os professores têm maior interesse no desenvolvimento de projetos em grupo do que no de monografias. Desde o primeiro ano do curso, os professores tentam estimular os alunos a desenvolverem a primeira modalidade de trabalho. Isto acontece também por uma questão de disponibilidade. Afinal, se todos os alunos resolvessem desenvolver monografias, cada professor teria de orientar, individualmente, uma média de 4,5 alunos. Nessas condiçōes, torna-se mais indicada a realização em grupo de projetos nas empresas. Em 2004, por exemplo, foram realizados seis projetos experimentais, que envolveram a participação de 24 alunos de um total de 28 concluintes, e elaboradas quatro monografias.

Para minorar a carência de professores, a partir de 1999 tentaramse mudanças no tocante à orientação, antes restrita aos professores de Relaçōes Públicas. Os alunos passaram a ter a liberdade de buscar, em outras áreas do conhecimento, orientadores para seus projetos. Porém, isso na prática não se concretizou. 
Além do número restrito de professores, há outras dificuldades no tocante à orientação de monografias. Alguns docentes perceberam que certas características imprescindíveis à elaboração desse tipo de trabalho - um elevado grau de disciplina do aluno, por ser um trabalho solitário, e um bom volume de leituras efetivadas em anos anteriores - com relativa frequência não se verificavam entre os alunos.

Observou-se que tais limitaçōes têm dificultado também a realização dos projetos experimentais. Porém, superálas não pode ser atribuição somente dos professores. Ela se constitui em uma tarefa de muitas mãos e envolve a dedicação tanto dos alunos quanto dos orientadores. A responsabilidade e o interesse do aluno é fundamental nesse processo, porque cria um elo de compromisso e de confiança entre o grupo e o seu orientador.

Ressalte-se outra importante questão enfrentada pelos professores. Às vezes, eles não têm como exigir dos alunos determinadas tarefas pertinentes aos projetos, porque a instituição não disponibiliza laboratórios e materiais. Alguns alunos pagam do próprio bolso a confecção de peças relativas ao projeto. No entanto, essa não é uma prática que pode ser exigida de todos.

Apesar das dificuldades que enfrentam durante a orientação de projetos e monografias, os professores têm um papel importante nos "rumos" que essa disciplina toma. Influenciam e direcionam a condução do trabalho e, nessa tarefa, percebem a necessidade de o curso de Relaçôes Públicas padronizar as orientações do corpo docente. Um padrão metodológico na orientação e na avaliação dos projetos facilitaria a criação e a implantação de uma cultura sistematizada nas orientaçôes, na avaliação de conteúdos, no rigor dos prazos e na discussão permanente dos professores sobre o andamento dos projetos experimentais.

Aos professores cabe tão-somente a orientação. Os projetos experimentais são desenvolvidos pelos alunos, que se responsabilizam pela escolha do orientador, da empresa cliente e do tema, pela formação do grupo e, principalmente, pelo modo de conduzir e realizar o projeto. O professor orientador incumbe-se do papel de facilitador da experiência e dele depende o bom aconselhamento dos alunos.

No que se refere à motivação da escolha do orientador, os alunos que cursavam o quarto ano de Relações Públicas em 2004 apontaram os seguintes aspectos: $50 \%$ responderam que buscam o professor pela capacidade, competência e experiência no assunto; $29 \%$ disseram que não tiveram opção; $7 \%$, pela disponibilidade; $7 \%$, pela afinidade, e outros $7 \%$, por ser o professor mais jovem e iniciante.

A opçáo dos alunos pelo tema e pela empresa exige maleabilidade dos professores, porque não perpassa pelas suas preferências pessoais nem por sua área de atuação ou formação. Essa maleabilidade é importante, pois permite aos alunos experimentar diversas áreas de atuaçáo, o que, por consequiência, abre caminhos para novos mercados e divulga a profissão em setores que antes não conheciam a aplicabilidade das Relações Públicas.

$\mathrm{Na}$ escolha do tema observou-se que, algumas vezes, o projeto experimental parecia conduzir o tema, e não o contrário. Essa observação, aparentemente simples, na realidade revela o modo como a experiência pode sofrer distorções, na clara intenção de "fazer" um prcjsto de sucesso. Essa prática, além de reafirmar a imaturidade dos alunos, revela também a pouca informação que se tem a respeito desse tipo de trabalho durante o tempo que precede sua realização. Observou-se que, nos projetos analisados, alguns chegaram à fase de execução sem embasamento em pesquisas, sem uma compreensão maior da realidade a que se propuseram analisar. Constituíam-se em simples tarefas de Relaçóes Públicas.

A escolha do tema, da empresa cliente e da metodologia utilizada são questôes importantes e interligadas. Afinal, os profissionais de Relaçóes Públicas defendem a posição de estrategistas, de gestores da comunicação, mas se o aluno tem 
apenas a idéia de realizar uma tarefa de sucesso, ele não se interessará em desenvolver a pesquisa e a análise situacional, essência da profissão, e que acaba sendo deixada de lado.

Por isso, é importante que os alunos tenham acesso às experiências que já foram desenvolvidas e saibam até mesmo a maneira como os egressos fizeram seus projetos. Porém, verificou-se que não existe na Facomb/UFG a preocupação em catalogar e arquivar os projetos dos alunos, referencial bibliográfico importante. Para a realização dessa pesquisa, contou-se com os projetos de posse de cada orientador. Por meio deles, verificou-se que, no período analisado, $47,61 \%$ dos projetos foram desenvolvidos na iniciativa privada; $23,80 \%$, em instituições públicas; $9,52 \%$, em empresas sem fins lucrativos, 4,79\%, em organizaçōes nãogovernamentais e $14,28 \%$, em outras. Existe uma tendência a preferir empresas privadas, pela oportunidade de emprego que elas oferecem.

Dentre as motivaçōes apontadas para a escolha da empresa cliente, destacam-se a facilidade de acesso, a oportunidade de emprego, o interesse na área em que a empresa atua e a sugestão do professor. Observou-se uma tendência a escolher a empresa cliente tomando-se por base a facilidade de acesso, ou seja, o conhecimento de alguém "lá dentro". Isto possibilita ao aluno ter um aliado, um facilitador da experiência na empresa. Esse facilitador pode fornecer informaçóes e até viabilizar uma aceitação maior do grupo por parte dos funcionários.

Os alunos que estavam desenvolvendo seus projetos de final de curso afirmaram que tiveram uma experiência muito válida no terceiro ano, em 2003. Duas professoras pediram trabalhos exploratórios em empresas. A passagem por todo o processo de escolha, visitas e conversas contribuiu tanto para amadurecer a visão com relação a algumas empresas goianas quanto para a aceitação que teriam quando fossem apresentar a proposta de realização do Projeto Experimental. Um dos grupos, inclusive, acabou desenvolvendo seu projeto prático na empresa em que fez esse estudo exploratório.

Há maior facilidade na escolha da temática e da empresa a ser trabalhada quando o grupo já tem em mente a especialidade das Relaçóes Públicas que mais the interessa. Durante a realizaçáo do grupo focal, os alunos disseram que os interesses dos componentes do grupo nem sempre convergem, mas que, definido o tema, é possível viabilizar o projeto a partir dos objetivos gerais do grupo. Isso só se torna possível porque o Projeto Experimental quase nunca se restringe a um só aspecto da comunicaçáo. Quase todos os projetos passam por um processo em que há a necessidade de análise estratégica da comunicação da empresa.

Os alunos pesquisados consideraram o trabalho em grupo uma forma riquíssima de trocar experiências, pois cada aluno tem uma vivência acadêmica e sociocultural muito particular. Eles enfatizaram que, em grupo, se reúnem pessoas diferentes em torno de um objetivo comum, o que propicia o florescimento de idéias e a criatividade. Em suma, o aprendizado no sentido mais amplo é posto à prova. Porém, só é possível alcançar esse nível de atuação quando a diversidade de experiências - o background - de cada aluno contribui de maneira bem específica na qualidade do projeto e os componentes conseguem administrar bem as diferenças e as colocam a serviço do projeto. No grupo, há uma reunião de personalidades e aptidōes diferentes; uns se interessam mais pela redação, outros pela pesquisa, outros pela análise dos dados colhidos e, assim, é possível criar uma verdadeira consultoria, em que cada um "trabalha" na sua especialidade.

O Projeto Experimental como uma disciplina acadêmica é, sobretudo, momento para revisão de conceitos e para discussão com o orientador. Uma equipe consegue tirar o máximo proveito desse trabalho se for capaz de detectar os problemas, trazê-los para a discussão com os professores e com os colegas e, do debate e da reflexão, descobrir meios de interagir e de agir sobre a realidade. 
Afinal, o principal objetivo dessa disciplina é aliar a teoria à prática, e não a prática em si.

\section{Considerações finais}

Apesar dos problemas detectados, os projetos experimentais são extremamente válidos como metodologia de ensino e aprendizagem. Nessa experiência, o aluno se torna capaz de depreender a realidade da profissão, de se avaliar como futuro profissional, detectando defasagens teóricas, comportamentais etc. Outro aspecto positivo é que a Universidade Federal de Goiás, instituição pública "sustentada" pelo contribuinte, nessa prática consegue alcançar um de seus objetivos: manter uma relação de troca com a comunidade. Nos projetos experimentais, os alunos prestam assessoria às empresas em que desenvolvem seus projetos e colocam a serviço da sociedade o conhecimento e o manejo da tecnologia aprendidos.

A experiência do projeto experimental, além de ser uma exigência legal para a colação de grau, permite uma formação mais completa do aluno. É perceptível o amadurecimento dos alunos no decorrer do projeto. Sua visão fica mais ampla e até sua capacidade de contextualizar os assuntos abordados em sala de aula fica maior: Exigidos com relação ao conteúdo teórico, muitas vezes os estudantes têm de "buscar na fonte", ou seja, voltam a estudar conteúdos que nos três primeiros anos de curso não mereceram deles a devida atenção.

Mesmo diante de tantos percalços, os professores também ganham com a orientação dos projetos. Eles percebem, por meio dos trabalhos e do diálogo com os alunos, as exigências que o mercado faz dos novos profissionais, a reação das empresas às propostas de comunicação etc. A experiência e o conhecimento acumulados lhes permitem, mesmo que acompanhando indiretamente, traçar um cenário representativo da situação do mercado de Relaçōes Públicas. Isso tem reflexos na adequação ou na introdução de assuntos abordados em sala de aula.

Para as empresas, a contribuição dos projetos experimentais pode ser significativa desde que o projeto seja de qualidade. Quando ele é realizado de maneira séria, a empresa cliente ganha uma análise da sua comunicação, em que os problemas e os pontos fortes são analisados de forma a otimizar seus esforços nesse setor.

Enfim, a disciplina Projeto Experimental contribui efetivamente para aqueles que se envolvem em sua realização, pois representa ganhos significativos, desde que seja encarado de maneira madura; viabiliza a condução do processo de formação acadêmica em um quadro de deficiência de pessoal docente; empresta um caráter prático à formação dos novos profissionais de Relaçōes Públicas, sem dissociação da teoria; possibilita a extensão da Universidade até a comunidade, promovendo o retorno a esta do saber construído, além de favorecer o contato dos novos profissionais com o mercado de trabalho e contribuir para a divulgação dessa importante área entre o empresariado.

Abstract

The "Experimental Projects" is a discipline of the Social Comunication Course and perform an important part in the student academic life. In 2004, with the objective of improve the understanding about this practice, it was developed a research whith teachers and the senior students of the Public Relations Course of Universidade Federal de Goiás. The purpose of this article is just approach a few important points of that research and contribute to teachers and students reflection about this subject.

Keywords: Experimental Projects; Public Relations; Comunication.

Referências

FREITAS, Sidnéia Gomes e FRANÇA, Fábio. Manual da qualidade em projetos de comunicação. São Paulo: Editora Pioneira, 1997.

KUNSCH, Margarida Maria Krohling. Relações Públicas e modernidade: novos paradigmas na comunicação organizacional. São Paulo: Summus, 1997.

MOURA; Cláudia Peixoto de. O curso de comunicação social no Brasil: do currículo mínimo às novas diretrizes curriculares. Porto Alegre, EDIPURCS, 2002. 